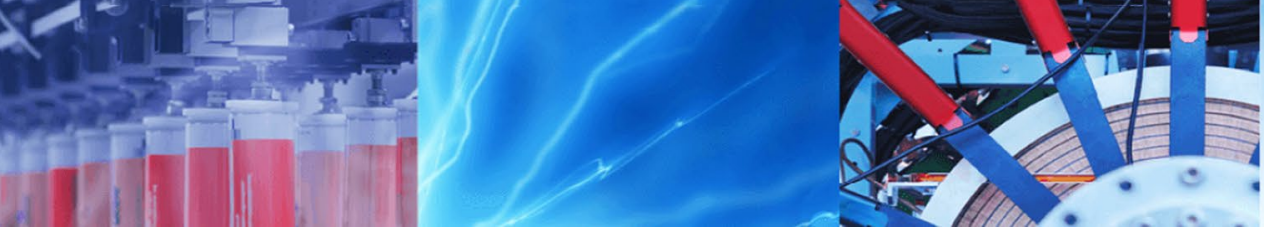

Research Article

\title{
Investigation on corrosion morphology and products of ancient tin amalgam mirrors by AFM, SEM-EDS and micro-Raman spectroscopies
}

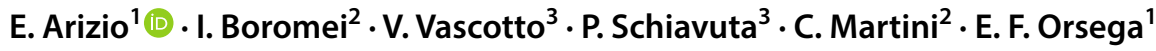

(c) Springer Nature Switzerland AG 2019

\begin{abstract}
This study detected and investigated the degradation effects and dynamics of the tin amalgam reflective layer of ancient mirrors. The experimental results have been obtained by different spectroscopic techniques: Light Microscopy, Scanning Electron Microscopy with Energy Dispersive X-ray Microanalysis (SEM-EDS), Atomic Force Microscopy (AFM) and $\mu$-Raman Spectroscopy. The latter two were applied for the first time to characterize the amalgam of ancient mirrors. Amalgam alteration products in form of concentric rings with alternate different compositions of tin oxides have been studied on both the amalgam reflective layer inner surface and on its cross-sections. For the first time SEM images of micro-crosssections of different amalgam degradation products, such as amalgam "drops" and craters, have been obtained. The size of the nano-particles of tin oxides, as amalgam degradation products, was estimated around 3-8 nm by AFM and micro-Raman, as already previously detected through TEM. Micro-Raman showed the presence of both cassiterite and romarkite nano-crystals forming the concentric rings, as only previously hypothesized. This investigation allowed to obtain further experimental evidence and a more advanced comprehension about the structure and formation phases of the amalgam decay products, giving further support to some statements by previous authors and suggesting some assertions different from the ones of previous studies.
\end{abstract}

Keywords Mirror · Amalgam · Corrosion · Cassiterite $\cdot$ Romarkite $\cdot$ Micro-Raman

\section{Introduction}

\subsection{Amalgam mirrors}

This study aims to deepen the understanding of dynamics and products of amalgam degradation in ancient amalgam mirrors. It led to new experimental evidence, obtained by multispectroscopic analyses of some samples of Venetian mirrors from the eighteenth century.

The majority of studies on amalgam ancient mirrors were performed in the last decade and concerned the characterization of the tin-mercury amalgam layer, whose interface with glass constitutes the reflective surface of the mirror [1-12]. They indicated that this reflective layer contains about $25 \mathrm{wt} \%$ mercury and $75 \mathrm{wt} \%$ tin and that it consists of two different phases: a solid one, distributed as "islands", composed by about 20 wt $\%$ mercury and 80 wt $\%$ tin, surrounded by a liquid phase composed by about 95-100 wt\% mercury and 0-5 wt\% tin [1-12]. The amalgam alteration involves mercury evaporation and formation of tin monoxide ( $\mathrm{SnO}$, romarkite) and dioxide $\left(\mathrm{SnO}_{2}\right.$, cassiterite). This causes the formation of amalgam drops and tin oxides craters [4-7, 11, 12]. In particular, the results of a recent study [11] suggested a possible mechanism of transformation from amalgam drops to craters.

E. Arizio, elenaarizio@virgilio.it | 'Department of Molecular Sciences and Nanotechnologies, Ca' Foscari University of Venice, Venice, Italy. ${ }^{2}$ Department of Industrial Engineering, University of Bologna, Bologna, Italy. ${ }^{3}$ Nanofab Labs, Veneto Nanotech (Nanotechnology Venetian Cluster), Venice, Italy. 


\subsection{Corrosion morphology}

Several studies among those cited above concern the alteration processes of the amalgam layer on the back side of ancient mirrors (interface amalgam-air) [1, 4-8, 10-12], while a recent study was based for the first time on the investigation of the amalgam side in contact with the glass (reflective surface) [12]. It highlighted the formation of a superficial morphology of the amalgam alteration products in form of concentric rings, with two alternate different compositions. These rings represent the superficial section of a system of hemispherical concentrically stratified calottes. They seem to have grown from an initial corrosion point on the air-interfaced surface towards the bulk, to reach the opposite reflective surface [12].

Similar patterns were found in some archaeological high tin bronze [13,14] and glass artifacts [15-17]. These banded structures constitute uncommon cases of corrosion and the composition of the rings and their formation mechanisms, related to corrosion processes of bronze, glass and mirror amalgam, remain still rather unclear.

This particular corrosion morphology, similar to the so-called Liesegang rings [18], could be associated to cyclical chemical processes, maybe related to periodical fluctuations of environmental conditions, such as temperature, humidity and $\mathrm{pH}$, depending on the nature of the involved materials and phenomena. It is nevertheless possible to suppose that these band structures depend simply on some intrinsic cyclical oxide-reductive process. In fact, Fink [19] observed that for archaeological bronzes, buried for hundreds of years in sites where the fluctuations of the above mentioned parameters were negligible, the sequence of corrosion rings cannot be related with environmental periodic variations.

Conversely, Scott [13] considered phenomena similar to a Liesegang process as responsible for the band structure found in ancient bronzes, and hypothesized that the banding phenomena could be related with the presence of tin in the alloy.

A deeper investigation on the mirror amalgam reflective surface could give additional information for understanding the amalgam alteration processes and the causes for the formation of these rings.

\subsection{Aim of the work}

This study aims to obtain further experimental evidence about degradation products and related corrosion morphology of the tin-mercury amalgam of ancient mirrors.
The investigation of the amalgam reflective side with different analytical techniques focused on the possibility to improve our understanding of the formation mechanism of the ring structures, at least about the sequence of the phases causing this final effect. The ultimate goal should be not only the full comprehension of these degradation phenomena, but the possibility to create the basis for setting up some techniques of inhibition of these degradation processes.

Light Microscopy (LM) and Scanning Electron Microscopy with Energy Dispersive X-ray Microanalysis (SEM-EDS) have been the preliminary tools to identify and characterize the banded structures. Atomic Force Microscopy (AFM) is proposed to investigate the tridimensional morphology of the corrosion products on the reflective surface of the samples. Both SEM-EDS and $\mu$-Raman analyses were aimed to detect further evidence about the composition of the concentric rings.

\section{Materials and methods}

A large number of flakes, detached from the degraded amalgam layers of 5 ancient amalgam mirrors, was studied. The flake detachment was due to the natural decay of the ancient mirrors so that its inner surface in contact with the glass sheet (reflective surface), flat, intact and not contaminated, could be investigated. The flakes analyzed had areas between 0.5 to $1.5 \mathrm{~cm}^{2}$ and thicknesses of about $50 \mu \mathrm{m}$.

The reflective surfaces of the flakes were first observed by LM and then studied by different analytical techniques, such as SEM-EDS, AFM and $\mu$-Raman Spectroscopy.

The light microscope used was a Leica MZ12.

SEM-EDS investigations were carried out using a Scanning Electron Microscope JEOL JSM 5900 equipped with X-ray microanalysis Oxford ISIS EDS with a $\mathrm{Si}(\mathrm{Li})$ detector. The samples were analyzed at low vacuum, with working distance around $10 \mathrm{~mm}$, beam voltage between 10 and $25 \mathrm{kV}$ and current between 0.01 and $10 \mathrm{nA}$. In the EDS maps the concentration ranges of every analyzed element have been represented in a color scale. Every color scale is independent from the other ones and hence the different color scales are not comparable.

AFM measurements were performed in air with a NOVA microscope equipped with a $10 \mathrm{~nm}$ curvature radius cantilever tip used in tapping mode. Lateral resolution was about $60 \mathrm{~nm}$, and the vertical one about $1 \mathrm{~nm}$. AFM scans were obtained on areas of $30 \times 30$ and $50 \times 50 \mu \mathrm{m}$ on flakes of very degraded amalgam.

Micro-Raman analyses were carried out with a Renishaw InVia Raman Microscope equipped with a green $\mathrm{Ar}^{+}$ion laser with wavelength $514 \mathrm{~nm}$ and power $50 \mathrm{~mW}$. The 
spectra were acquired in the range $100-1000 \mathrm{~cm}^{-1}$, with an exposure of $10 \mathrm{~s}$ and accumulation number between 10 and 20. The laser power used was between 1 and $10 \%$. The different areas of the samples were investigated by long working distance objectives of different magnifications $(20 \times, 50 \times$ and $100 \times)$.

SEM-EDS, AFM and $\mu$-Raman surface analyses were performed on flake samples of a very degraded amalgam portion, fixed by a carbon double-sided adhesive tape on an aluminum sample holder. Flakes were directly detached from the glass by the adhesive tape laying onto the back side of a degraded amalgam mirror, immediately inspected without further handling.

Cross-sections of the amalgam flakes were prepared by standard metallographic techniques (using transparent epoxy resin, grinding with $\mathrm{SiC}$ papers from P180 to
P4000 and polishing with diamond suspensions) and then inspected by a LM and SEM-EDS.

\section{Results and discussion}

\subsection{Light microscope investigation}

The reflective surfaces of different flakes have been observed by LM. They are presented in Figs. 1, 2 and 3 . They show some patterns of a very degraded amalgam layer: all samples show the presence of many structures of different size characterized by concentric bright and dark rings.
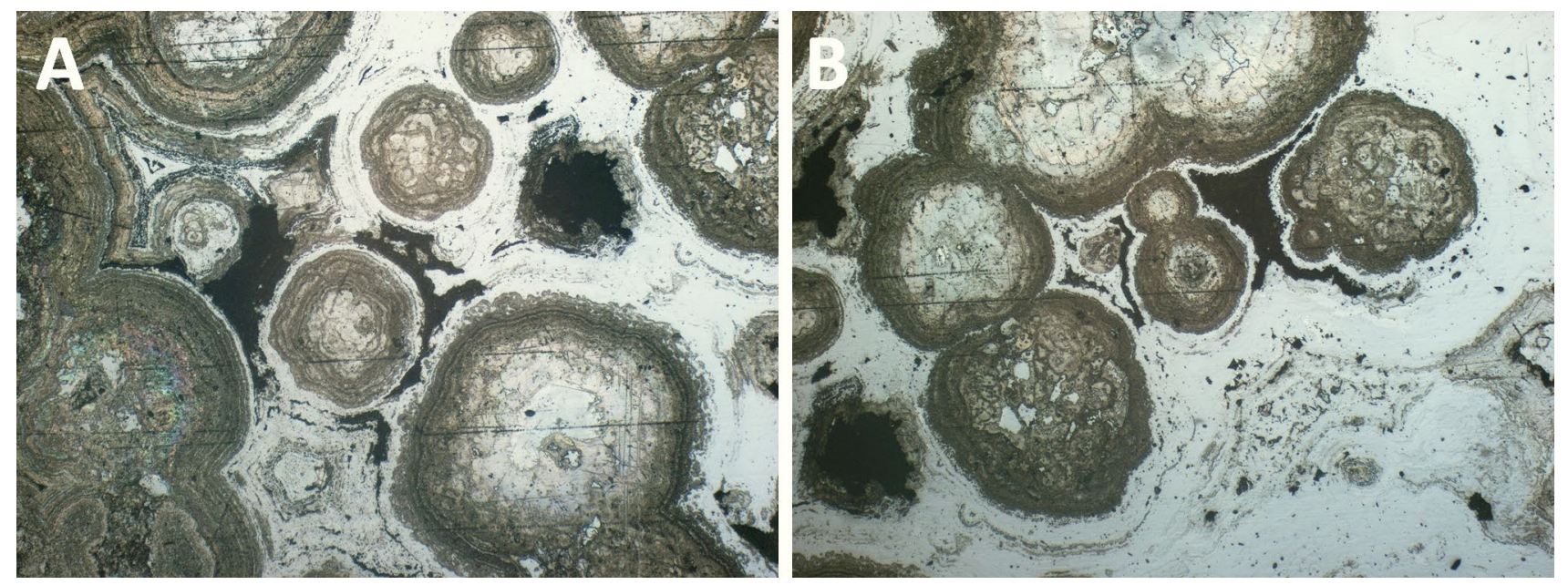

Fig. 1 LM images $(\times 25)$ of some banded structures on the reflective side of the amalgam layer
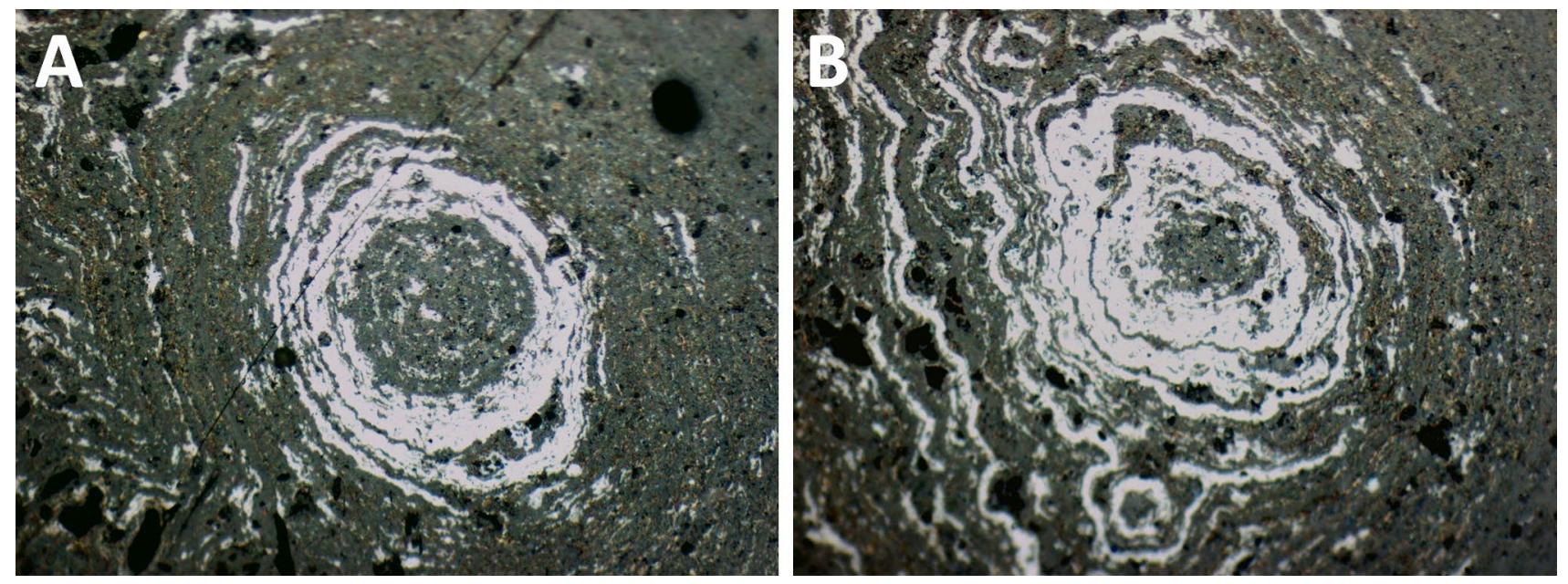

Fig. 2 LM images $(\times 100)$ of a single banded structure on the reflective side of the amalgam layer 

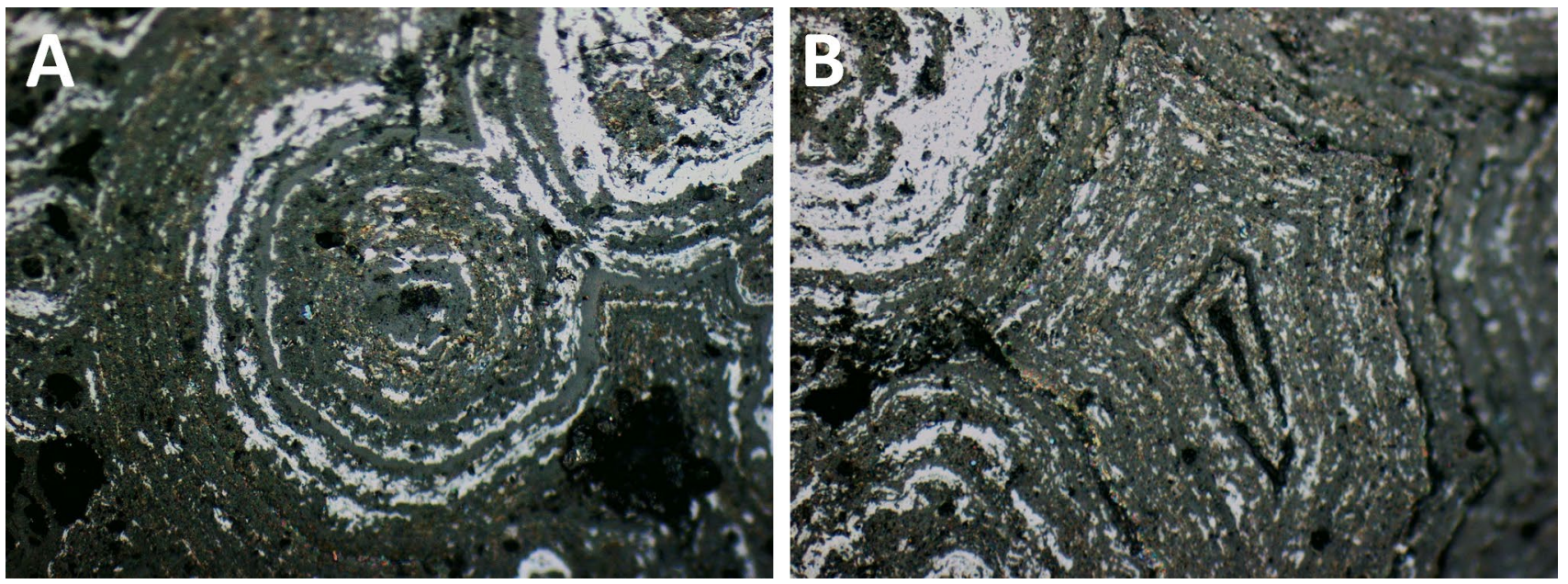

Fig. 3 LM images $(\times 200)$ of some differently banded structures on the reflective side of the amalgam layer

\subsection{SEM-EDS investigation}

Some SEM backscattered electrons images of the amalgam layer in cross sections were recorded in order to get information about morphology and composition of the corrosion products. It is the first time that images of cross sections involving amalgam drops and tin oxide craters have been obtained.

In these images it is possible to recognize the different steps of the corrosion processes, already presented in a previous work on surface images [11].

The Figs. 4 and 5 show cross sections of different areas of a flake: it is worth noting the formation of a layer of tin oxides of about $50 \mu \mathrm{m}$ thickness together with amalgam drops (Fig. 4) and craters (Fig. 5). Drops are present also on the top of some well pronounced craters, as previously detected [4-7, 10-12]. SEM pictures in Fig. 4a, b showed that they are formed by the two phases of the tin amalgam, in contrast with previous studies, where the drops were characterized as rich in mercury [11] or described as formed almost entirely by mercury [4-7]. In summary, the darker and lighter zones in Figs. 4 and 5 consist of tin oxide and mercury-tin amalgam respectively. Figures 4 and 5 show, moreover, sequential oxidation steps of the amalgam layer: (1) the amalgam drop is surrounded by tin oxides (Fig. 4a), (2) the oxide layer growing around the amalgam drop (Fig. 4b, c), (3) the so called "crater" produced by further growth of the tin oxides around the amalgam drops, with some amalgam remaining on the top of the crater (Fig. 4d, e) and (4) the crater completely formed, without amalgam residues on its top (Fig. 4f).

This sequence, only supposed in a previous study [11] by the SEM surface observation of a large area of the amalgam back side, is now shown also in a cross-section, and evidenced by the pattern of the subsequent rings along the crater (Fig. 4c, d).

Figures 4 and 5 show that even the craters are formed by subsequent rings, as the calottes found on the reflective surface of the degraded amalgam.

The secondary electron image of the reflective surface of a flake (Fig. 6b) shows that its surface (BE SEM image in Fig. 6a) is almost flat even at the microscopic level. This morphology of the reflective surface is due to the compression of the alteration compounds against the glass flat sheet during the expansion of the corrosion towards the reflective surface.

In the images in Fig. 7 it is possible to observe that the banded structures have different shapes and features: some of these consist of almost circular rings and of a dark central area (Fig. 7a), while in other ones the ring patterns are irregular and weakly pronounced, often with a zone of not corroded amalgam (Fig. 7b), or a hole at the center (Fig. 7c). These differences may be ascribed to the different evolution step of the corrosion process in different areas.

The darker area in the centre of the structure (Fig. 7a) may correspond to a hemispherical calotte center at the surface. As hypothesized in previous studies on the basis of experimental evidence, the corrosion should start at the back free surface of the amalgam layer and grow as a hemispherical calotte into the bulk of the amalgam layer $[3,11$, $12]$. When the growth of a calotte reaches the reflective surface adherent to the glass sheet, the calotte can expand only two-dimensionally and it is detected as superficial ring structure on the reflective surface.

Otherwise, the presence of the amalgam at the center (Fig. 7b) of a banded structure may indicate that the observed area corresponds, on the reflective surface, to an amalgam drop partially surrounded by tin oxides, like the one shown in Fig. 4b. The image in Fig. 7b could therefore 

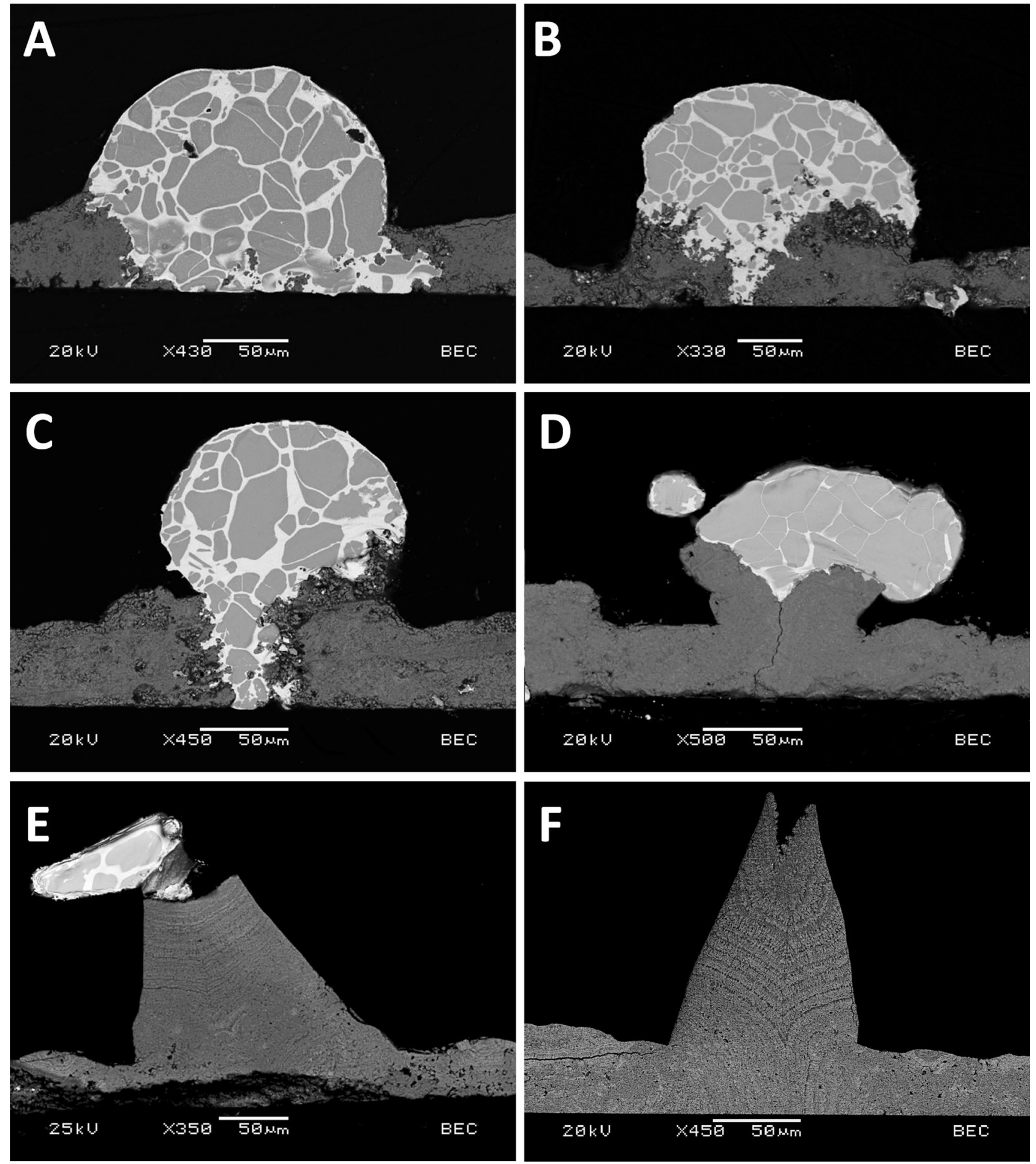

Fig. 4 SEM images in backscattered electrons of a cross section of a degraded amalgam reflective layer flake, showing the tin oxide layer and amalgam drops and craters at different magnifications. The images $\mathbf{a}-\mathbf{f}$ show the sequential oxidation of the amalgam layer

correspond to the morphology on the reflective surface of the flake shown by the cross section of Fig. $4 \mathrm{~b}$.

The presence of a hole in the centre (Fig. 7), instead of the amalgam as in Fig. 7b, could indicate a subsequent degradation step of the structure in Fig. 7b, when all the amalgam of a drop is corroded forming the crater, leaving the central area empty. 

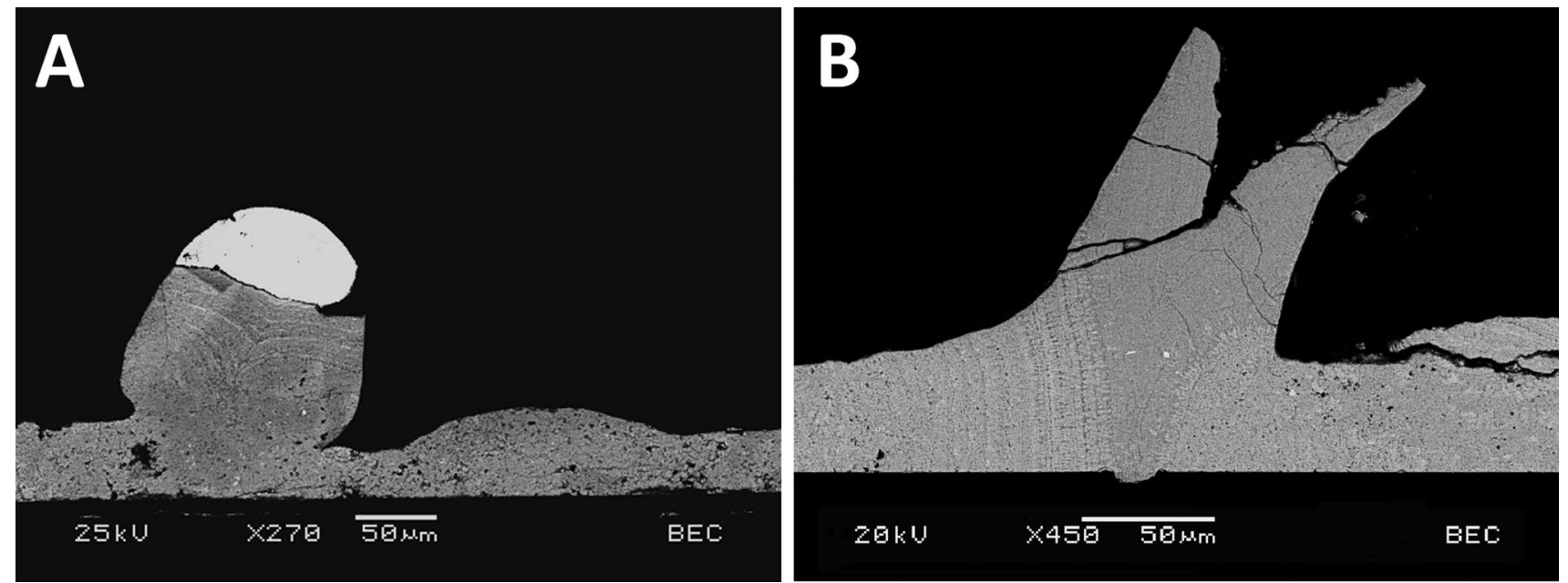

Fig. 5 SEM images in backscattered electrons of a cross section of a degraded amalgam reflective layer flake; $\mathbf{a}$ the tin oxide layer and a crater with an amalgam drop on the top; $\mathbf{b}$ the tin oxide alone after the detachment of the amalgam drop
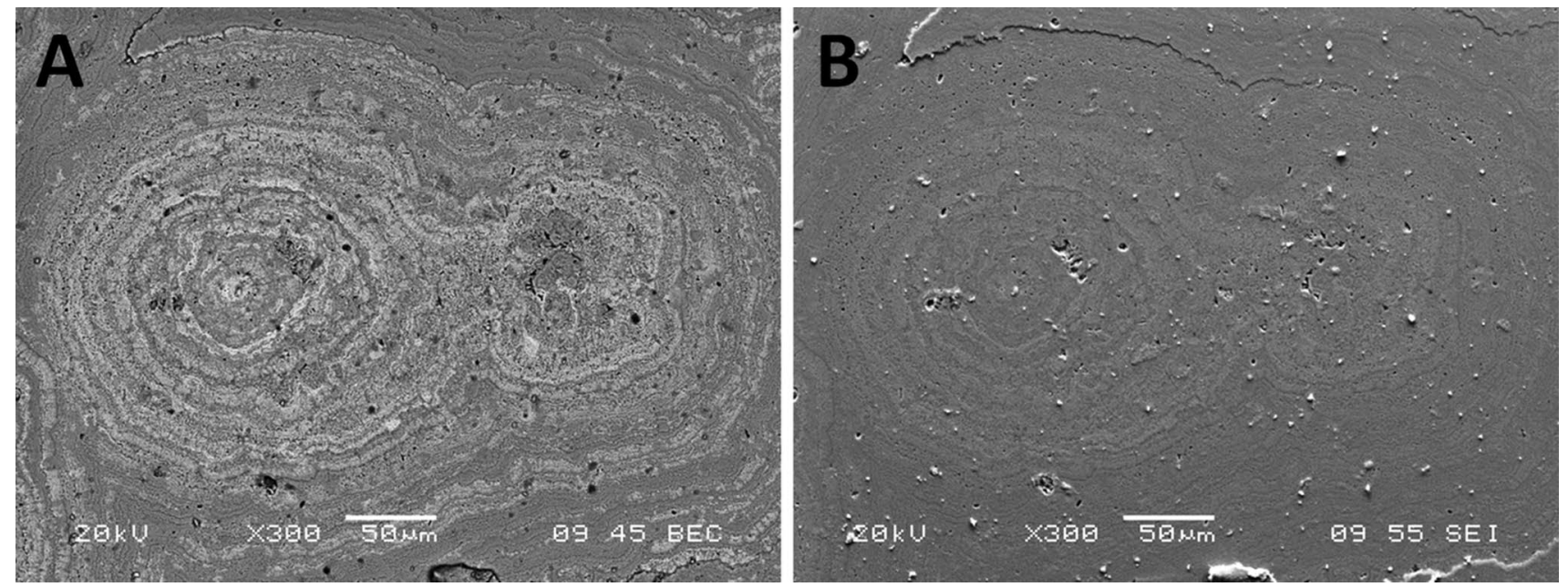

Fig. 6 SEM images of the reflective surface of the degraded amalgam layer with banded structures; $\mathbf{a}$ backscattered electrons image; $\mathbf{b}$ secondary electrons image
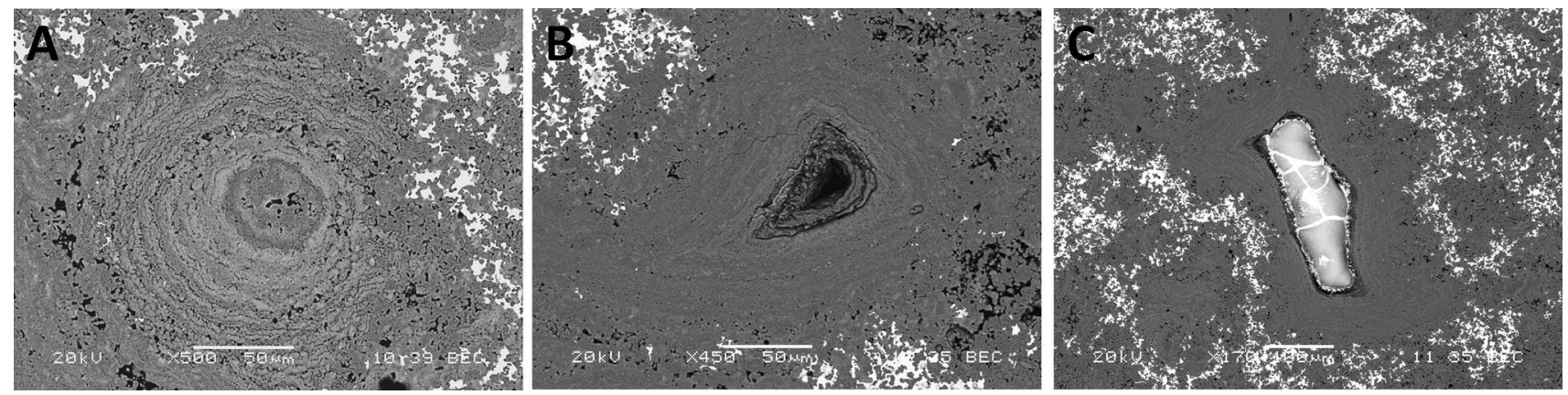

Fig. 7 SEM backscattered images of the reflective surface of the degraded amalgam layer with different corrosion patterns; a banded structure with circular rings and a dark central area; b banded structure with a zone of uncorroded amalgam at the center; $\mathbf{c}$ banded structure with a hole in the center

\section{SN Applied Sciences}


SEM-EDS maps showed that the dark center and the external rings of the banded structure have different tin contents [12]. Localised EDS measurements indicated that the darker areas are mostly constituted by cassiterite and the grey ones by romarkite.

These results are strengthened by the SEM-EDS X-ray maps of Fig. 8 that show more clearly that the subsequent rings have alternatively two different compositions. The anti-correlation between the $\mathrm{Sn}$ and the $\mathrm{O}$ maps seems to indicate that the rings are formed by different mixtures of the two tin oxides, romarkite and cassiterite.
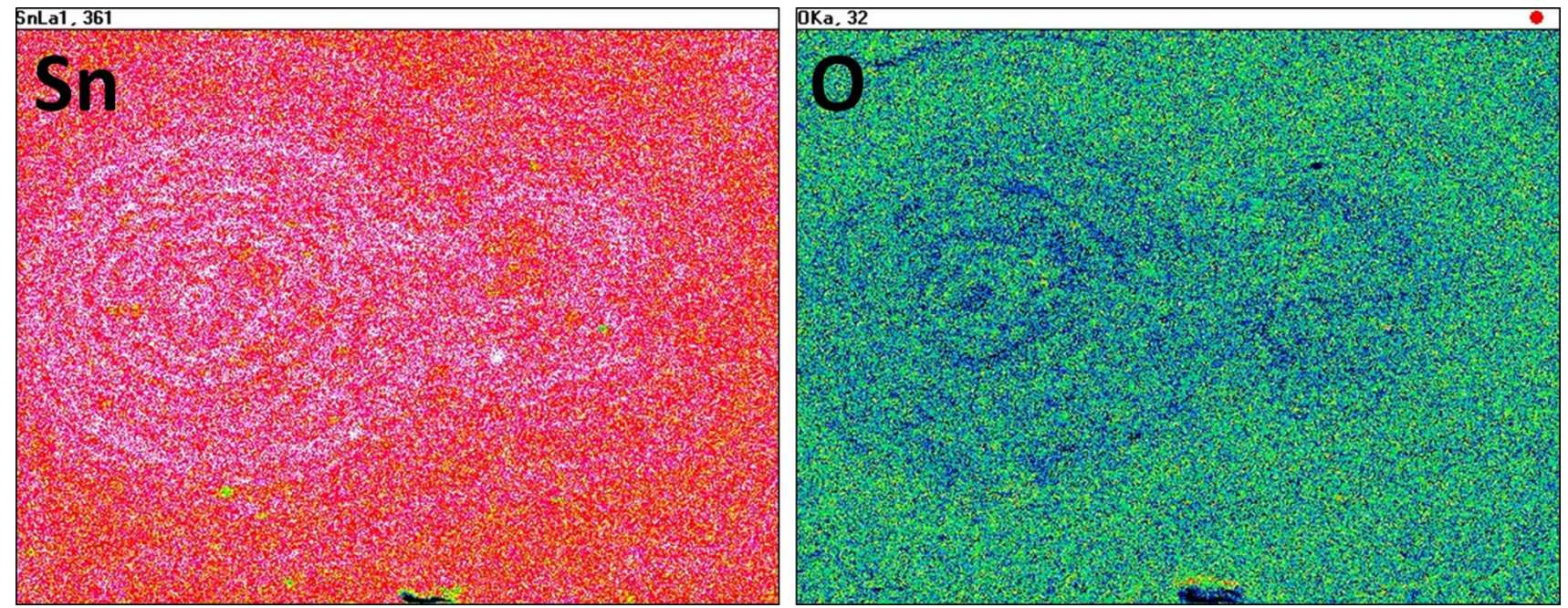

Fig. 8 EDS maps of Sn and O of the area in Fig. 6
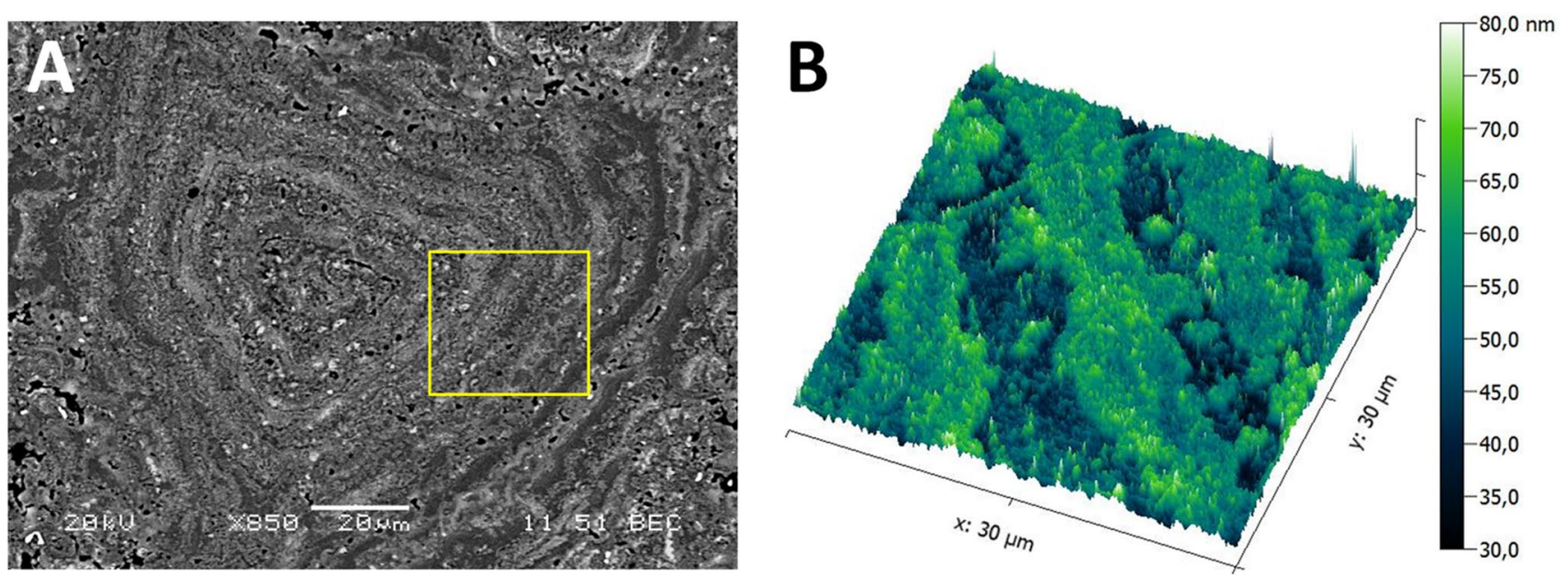

Fig. 9 a SEM image $(\times 850)$ of a banded structure on the reflective surface of the degraded amalgam layer; $\mathbf{b}$ AFM scan of the yellow square area of Fig. $9 a$ 
thicknesses of the rings may suggest a process in which two different phases of tin oxidation and precipitation happen subsequently, or the presence of two different oxidation states.

In spite of the high spatial resolution (about $60 \mathrm{~nm}$ ), AFM scans did not detect the presence of crystal particles, indicating particle sizes smaller than the scan resolution. This is in agreement with Herrera et al. [7], who described the presence of tin oxide nanoparticles in amalgam mirrors. These authors detected and measured by X-ray Diffraction and Transmission Electron Microscopy, $\mathrm{SnO}_{2}$ nanocrystals of about 4-5 $\mathrm{nm}$ average size [7].

AFM measurements with a higher resolution in order to detect the presence of nanocrystals led to artifacts and not clear scans. It must be considered that the surface of the analyzed samples is porous and can contain traces of mercury and dust particles absorbed after the flake detaching.

\subsection{Micro-Raman}

In order to identify the tin alteration compounds forming these concentric ring structures, a $\mu$-Raman investigation was carried out on the flake samples, on both the bright and dark areas of a ring structure.

Figure 10b shows the Raman spectrum of the central bright area of Fig. 10a. The spectrum is characterized by a strong peak at about $210 \mathrm{~cm}^{-1}$, related to romarkite (SnO) [20], probably as nanocrystals, as suggested by AFM. Figure $11 \mathrm{~b}$ shows the Raman spectrum of the central dark area of Fig. $11 \mathrm{a}$. The spectrum shows the presence of the romarkite peak at $210 \mathrm{~cm}^{-1}$ and of a broad peak at about $633 \mathrm{~cm}^{-1}$, distinctive of cassiterite crystals $\left(\mathrm{SnO}_{2}\right)$ [21-23].

A broad band between 400 and $800 \mathrm{~cm}^{-1}$, with a maximum at about $575 \mathrm{~cm}^{-1}$, is also present in the spectra in Figs. $10 \mathrm{~b}$ and $11 \mathrm{~b}$. This band was found in several studies

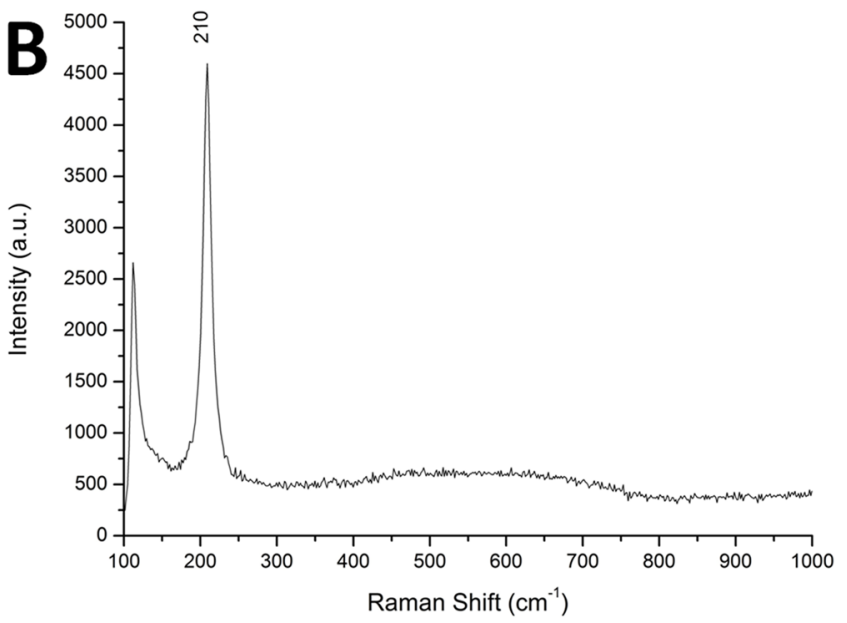

Fig. 10 a Optical image of a bright ring of the banded structure; b Raman spectrum acquired on the bright area at the center of Fig. 10a
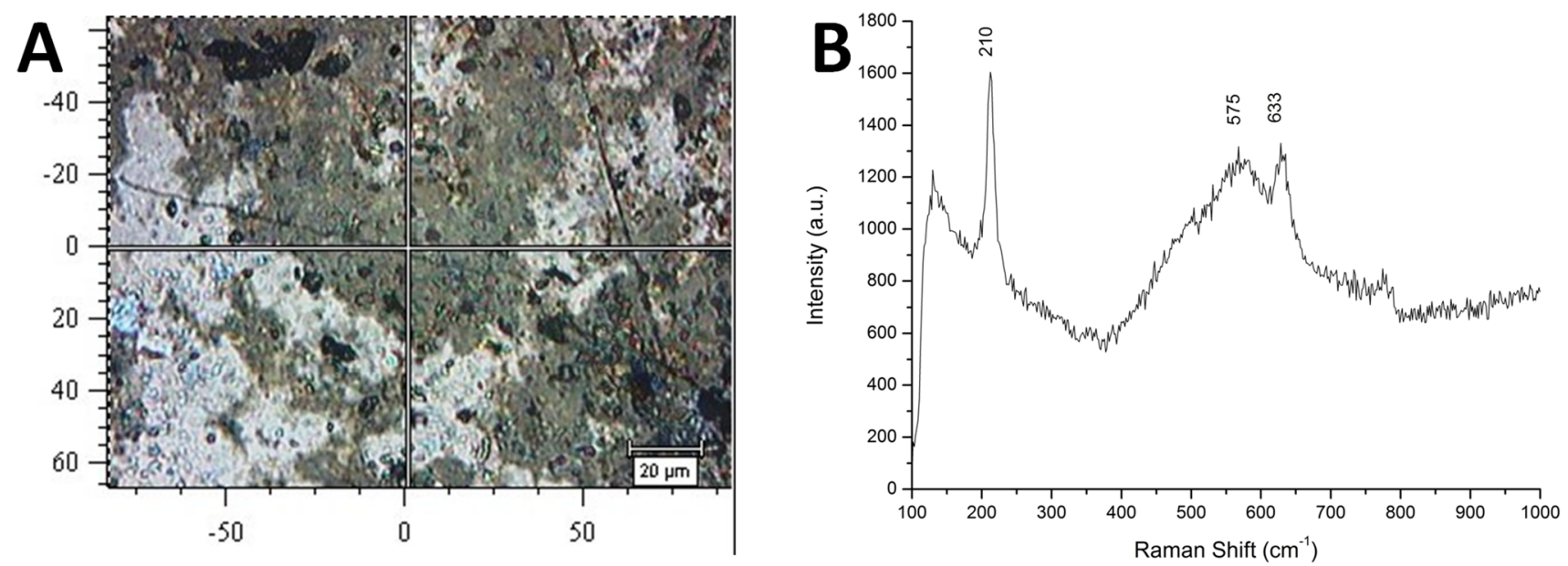

Fig. 11 a Optical image of a dark ring of the banded structure; b Raman spectrum acquired on the dark area at the center of Fig. 11a 
on cassiterite nanoparticles and can be due to the very small size of the particles $[21,24,25]$.

According to Dieguez et al. [21], who characterized by TEM cassiterite particles with different sizes obtained by calcinating $\mathrm{SnO}_{2}$ nanoparticles at different temperatures, it is possible to estimate the linear size of the $\mathrm{SnO}_{2}$ particles from the study of the Raman spectrum major peaks.

In his work, Dieguez et al. [21] demonstrated that there is a correlation between the cassiterite nanoparticles size and the peaks shift in the Raman spectra (see Table 2 in Ref. 21). According to this study, the maximum at $633 \mathrm{~cm}^{-1}$ ( $m$ ode $\mathrm{A}_{1 \mathrm{~g}}$ ) and the maximum of the broad band at around $575 \mathrm{~cm}^{-1}$ (mode S1) allow to assign to the particles sizes in the range 3-8 $\mathrm{nm}$, taking in account the calculated precision reported in the Ref. 21 , where no accuracy determination is considered.

Cassiterite crystals were already found by XRD in previous studies $[1,3,4]$ but this technique did not allow to find the presence of cassiterite nanocrystals and to determine the composition of the single ring structures.

The AFM and the micro-Raman analyses of the present study allowed to determine the presence not only of cassiterite nanocrystals as degradation product of amalgam, as suggested by Herrera et al. [7], but also the presence of romarkite nano-crystals in the concentric rings.

Moreover, these results allowed to state that the bright areas shown by SEM images correspond to the white ones detected by LM observation and, vice versa, that the SEM dark looking areas correspond to the dark ones observed by microscopic inspection.

The Raman maps in Fig. 12b, d illustrate the pattern of different corrosion products in the same area as shown in Fig. 12a. Some areas are rich in romarkite (Fig. 12b) and poor in cassiterite (Fig. 12c, d).

By means of this micro-Raman investigation it is thus possible to assume that the bright rings of the concentric structures are formed mostly by romarkite nanocrystals and the dark ones are composed by a mixture of cassiterite and romarkite nanocrystals. These results are in agreement with the localised EDS measurement on the rings by Arizio et al. [12] that suggested that the two areas are differently rich of the two tin oxides romarkite $(\mathrm{SnO})$ and cassiterite $\left(\mathrm{SnO}_{2}\right)[12]$.

\subsection{Decay mechanism}

The non-degraded tin amalgam of mirrors consists of a layer about $0.1 \mathrm{~mm}$ thick, composed of two phases with different contents of tin and mercury.

Previous studies $[1,10]$ on amalgam of ancient mirrors demonstrated, by artificial aging, that the size of the crystalline solid phase grows with the amalgam age to reach a maximum size. This seems to be due to the rearrangement of the phases because of the natural evaporation (and loss) of mercury mostly from the liquid phase. In fact, as long as the liquid phase is in excess, mercury evaporation causes the approach of the solid phase crystals to each other. When the liquid phase amount is no more sufficient to surround the solid phase crystals, the solid phase re-arranges, creating crystals of larger sizes, so that a smaller volume of liquid phase is necessary to surround them.

When the solid phase crystals reach their maximum size $[1,10]$, further mercury evaporation leads to the precipitation of excess tin and oxidation can start from the back side of the mirror in contact with the atmosphere. The tin particles oxidized on the back side are thus the nucleus of the calottes growing in the bulk of the amalgam layer to reach the opposite front of the reflective surface, as found in the previous studies $[3,12]$.

Instead of conventional tin oxidation mechanisms, that cause the formation of a tin oxide passivation layer, in this case the degradation products are probably porous, allowing the diffusion of oxygen in the deeper layers, forming the oxide calottes. This continuous oxidation can also be promoted by the continuous $\mathrm{Hg}$ evaporation from the not still degraded amalgam.

The oxidation process causes the reduction of the amalgam volume of around $50 \%$ with respect to the original
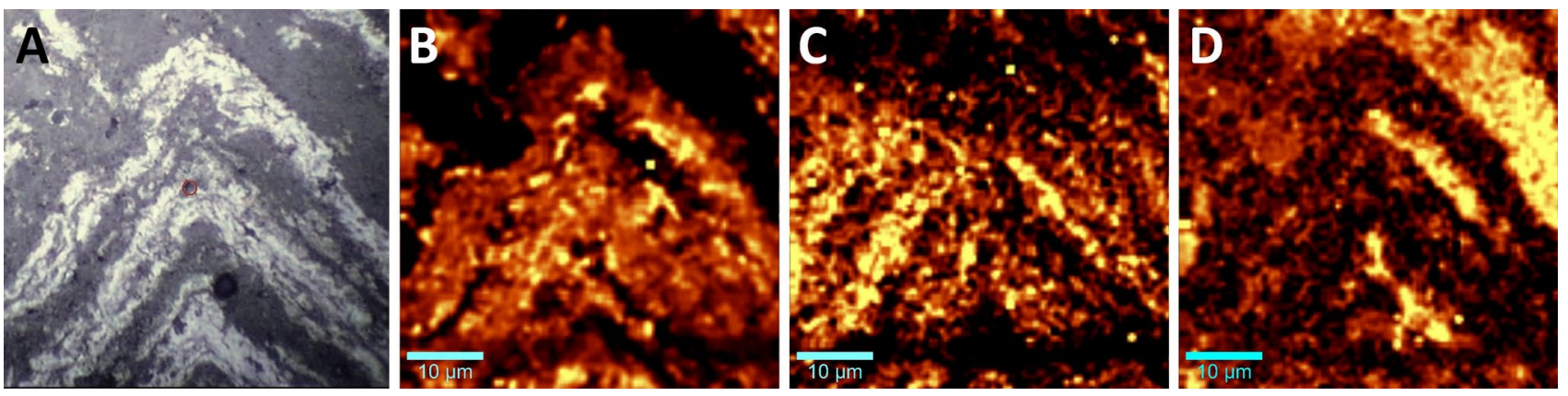

Fig. 12 a Optical microscope image of some rings; b Raman map of the $210 \mathrm{~cm}^{-1}$ peak ascribable to romarkite; c Raman map of the $630 \mathrm{~cm}^{-1}$ peak ascribable to cassiterite; $\mathbf{d}$ Raman map of the $580 \mathrm{~cm}^{-1}$ peak ascribable to cassiterite 
one: the thickness of the oxidized layer is usually around $50 \mu \mathrm{m}$.

Because of its high surface tension and the volume reduction due to both mercury evaporation and tin oxidation, the remaining non-degraded amalgam is visible as amalgam drops on the back surface. The growth of the tin oxides around the amalgam drops causes the formation of the craters found in the previous studies, until no amalgam or mercury is present on their top.

The presence of hemispherical layers of tin oxides could indicate that the amalgam progressive corrosion process involves cyclic phases. Presently, no clear experimental evidence is available to clearly state the origin of the presence of alternate layers of different composition. They could depend on the variation of environmental parameters, such as temperature or humidity, or be due to intrinsic features related to composition of amalgam and to oxidation/precipitation processes.

\section{Conclusions}

This study focused on the investigation of degradation of the reflective surface of ancient amalgam mirrors. The degradation processes have been examined through the analytical results obtained by different spectroscopic techniques: SEM-EDS and for the first time AFM and microRaman have been used to characterize tin amalgam and degradation products of ancient mirrors.

This combination of techniques allowed to deepen the knowledge on the amalgam reflective layer and to clarify morphologies and processes about its decay products, leading to some considerations differing from those made in previous studies.

For the first time, SEM images of cross-sections of different amalgam degradation products, such as amalgam "drops" and craters, were obtained. They show that the forms previously described as "mercury rich drops" or "mercury spheres" are instead composed by bi-phasic, non-degraded amalgam.

Differently from some previous studies, by microRaman analyses was possible to detect both romarkite and cassiterite as degradation compounds of the amalgam layer.

Some new experimental evidence gave further support to previous assertions: AFM and the micro-Raman analyses detected the presence of nanocrystals, as previously suggested. They also allowed to estimate the size of the nanoparticles around 3-8 $\mathrm{nm}$, as already previously detected through TEM.

Moreover, Micro-Raman analyses detected the presence of both cassiterite and romakite nano-crystals forming the concentric rings consisting of amalgam degradation products, as hypothesized only in a previous study on the basis of some SEM-EDS results.

The analysis of the concentric calottes, performed with different analytical techniques on both plane and crosssection led to a deeper understanding of the amalgam degradation products and allowed to explain more clearly structures and processes of the amalgam decay products.

Lastly, this investigation allowed to propose a general macroscopic amalgam decay mechanism defining its subsequent phases. It remains still unclear the origin of the formation of the subsequent calottes with two alternate different compositions, evidenced as Liesegang-like rings. They could depend on cyclic variation of environmental parameters or on intrinsic chemical/physical features of the amalgam system.

\section{Compliance with ethical standards}

Conflict of interest The authors declare that they have no conflict of interest.

\section{References}

1. Hadsund P (1993) The tin mercury mirror: its manufacturing technique and deterioration processes. Stud Conserv 38:3-16

2. Angelini E, Grassini S, Rosalbino F (2004) The mirrors of Villa della Regina in Turin: study of manufacturing and deterioration processes. Sci Technol Cult Herit 13:117-125

3. Zywitzki O, Nedon W, Kopte T, Modes T (2008) Characterisation of baroque tin amalgam mirrors of the historical Green Vault in Dresden. Appl Phys A 92:123-126

4. Herrera LK, Duran A, Franquelo ML, Gonzàles-Elipe AR, Espinós JP, Rubio-Zuazo J, Castro GR, Justo A, Peres-Rodriguez JL (2008) Study by grazing incident diffraction and surface spectroscopy of amalgams from ancient mirrors. Cent Eur J Chem 7:47-53

5. Herrera LK, Duran A, Franquelo ML, Jimenez de Haro MC, Justo Erbez A, Perez-Rodriguez JL (2008) Studies of deterioration of tin-mercury alloy within ancient Spanish mirrors. J Cult Herit 9:41-46

6. Herrera LK, Duran A, Franquelo ML, Justo A, Peres-Rodriguez JL (2009) $\mathrm{Hg} / \mathrm{Sn}$ aqmalgam degradation of ancient glass mirrors. J Noncryst Solids 355:1980-1983

7. Herrera LK, Justo A, Peres-Rodriguez JL (2009) Study of nanocrystalline $\mathrm{SnO}_{2}$ particles formed during the corrosion processes of ancient amalgam mirrors. J Nano Res 8:99-107

8. Lerf A, Wagner FE, Herrera LK, Justo A, Munoz-Paez A, PerezRodriguez JL (2016) Study of tin amalgam mirrors by $119 \mathrm{Sn}$ Mössbauer spectroscopy and other analytical methods. Hyperfine Interact 1:1. https://doi.org/10.1007/s10751-016-1279-4

9. Torge $M$, Krug S, Bücker M, Feldmann I, Scharf $H$, Witthuhn $H$ (2010) Investigation of mercury emissions of historic tin-mercury-mirrors, glass and ceramic conservation. In: Iterim meeting of the ICOM-ICC working group, October 3-6 Corning, NY, USA, pp 156-163

10. Arizio $E$, Orsega EF, Falcone $R$ (2013) Artificial aging of tin amalgam mirrors: a preliminary study of alteration compounds and kinetics. Procedia Chem 8:3-10 
11. Arizio E, Orsega EF, Sommariva G, Falcone R (2013) Tin amalgam mirrors: investigation by XRF, SEM-EDS, XRD and EPMA-WDS mapping. Appl Phys A 111:733-745

12. Arizio E, Orsega EF, Falcone R, Vallotto M (2014) EDS and $\mu-X R F$ mapping of amalgam degradation products in ancient mirrors. Environ Sci Pollut Res. https://doi.org/10.1007/s1135 6-013-2129-4

13. Scott DA (1985) Periodic corrosion phenomena in bronze antiquities. Stud Conserv 30:49-57

14. Ingo GM, De Caro T, Riccucci C, Khosroff S (2006) Uncommon corrosion phenomena of archaeological bronze alloys. Appl Phys A 83:581-588

15. Van Elteren JT, Izmer A, Šala M, Orsega EF, Šelih VS, Panighello S, Vanhaecke F (2013) 3D laser ablation-ICP-mass spectrometry mapping for the study of surface layer phenomena: a case study for weathered glass. J Anal Atom Spectrom. https://doi. org/10.1039/C3JA30362D

16. Dal Bianco B, Bertoncello R, Milanese L, Barison S (2005) Glass corrosion across the Alps: a surface study of chemical corrosion of glasses found in marine and ground environments. Archaeometry 47:351-360

17. Dal Bianco B, Bertoncello R, Milanese L, Barison S (2004) Glasses on the seabed: surface study of chemical corrosion in sunken Roman glasses. J Noncryst Solids 343:91-100

18. Liesegang RE (1896) Ueber einige Eigenschaften von Gallerten. Naturwissenschaftliche Wochenschr 11(30):353-362

19. Fink CG (1948) The corrosion handbook. HH Uhlig, New York, pp 103-104
20. Chen X, Grandbois M (2013) In situ Raman spectroscopic observation of sequential hydrolysis of stannous chloride to abhurite, hydroromarchite, and romarchite. J Raman Spectrosc 44:501-506

21. Dieguez A, Romano-Rodriguez A, Vila A, Morante JR (2001) The complete Raman spectrum of nanometric $\mathrm{SnO}_{2}$ particles. J Appl Phys 90(3):1550-1557

22. Huang BX, Tornatore P, Li YS (2000) IR and Raman spectroelectrochemical studies of corrosion films on tin. Electrochim Acta 46:671-679

23. Ocana M, Serna CJ, Garcia-Ramos JV, Matijević E (1993) A vibrational study of uniform $\mathrm{SnO}_{2}$ powders of various morphologies. Solid State lonics 63:170-177

24. Bazargan S, Heinig NF, Pradhan D, Leung KT (2011) Controlled growth of monodisperse nanocrystallites in tin(IV) oxide nanofilms. Cryst Growth Des 11:247-255

25. Rumyantseva M, Zhurbina I, Varechkina E, Badalyan S, Gaskov A, Timoshenko V (2010) Extraordinary stability of structural and electronic properties of tin oxide nanoparticles formed by soft chemistry. Adv Sci Tech 75:36-42

Publisher's Note Springer Nature remains neutral with regard to jurisdictional claims in published maps and institutional affiliations. 